\title{
O CINEMA NEONOIR ITALIANO E SUA ABORDAGEM EM L'ULTIMO CAPODANNO
}

ITALIAN NEONOIR CINEMA AND ITS APPROACH IN L'ULTIMO CAPODANNO

\section{Alexandre Rossato Augusti}

Doutor em Comunicação Social pela Pontifícia Universidade Católica do Rio Grande do Sul (Porto Alegre/Brasil).

Professor na Universidade Federal do Pampa (São Borja/Brasil).

E-mail: alexandreaugusti@unipampa.edu.br 


\section{Brazilian

\section{RESUMO}

A proposta deste artigo é a de verificar traços do cinema noir em um filme italiano que rompe com o período que na Itália é tradicionalmente compreendido como o do cinema noir clássico. Para além disso, a obra analisada, L'ultimo capodanno (MARCO RISI, 1998), pode ser facilmente percebida como pertencente ao gênero comédia. No entanto, empreende-se aqui uma tentativa de orientar para um olhar mais complexo sobre ela, identificando-se elementos do cinema noir ou neonoir e situando-os em uma narrativa que a priori conduziria acentuadamente para uma outra noção de gênero. Como orientação metodológica, aponta-se a análise filmica, destacando-se principalmente os autores Jacques Aumont e Michel Marie (2009), e Francis Vanoye e Anne Goliot-Lété (2009). Defende-se que L'ultimo Capodanno se trata de um filme neonoir, que rearranja elementos do noir clássico, tratados em condições particulares, contribuindo deste modo para uma nova alternativa de manifestação deste gênero em sua condição neonoir.

Palavras-chave: Cinema noir italiano. Cinema neonoir italiano. L'ultimo capodanno. Análise fílmica.

\section{ABSTRACT}

The proposal of this paper is to verify traits of noir cinema in an italian movie that breaks up with the period that in Italy is traditionally comprehended as that of the classic noir cinema. Furthermore, the analyzed work, L'ultimo capodanno (Marco Risi, 1998), can be easily noticed as belonging to the comedy genre. However, it is undertaken here an attempt to guide a more complex view over it, identifying elements of noir or neonoir cinema and placing them in a narrative that a priori would sharply lead to another notion of genre. As methodological guidance, it is pointed the film analysis, highlighting mainly the autors Jacques Aumont and Michel Marie (2009) and Francis Vanoye and Anne Goliot-Lété (2009). It is defended that L'ultimo capodanno is a neonoir movie that rearranges elements of the classic noir, treated in particular conditions, thus contributing for a new alternative of manifestation of this genre in its neonoir condition.

Keywords: Italian noir cinema. Italian neonoir cinema. L'ultimo capodanno. Film analysis. 


\section{Brazilian \\ Creative Industries}

\section{INTRODUÇão}

Pensar o cinema noir sugere uma série de considerações quanto aos seus possíveis contornos e pareceres diversos sobre suas possibilidades de continuidade, para além daquilo que se convencionou chamar de noir clássico, problematização que será apresentada adiante e desenvolvida no decorrer do texto. Entretanto, a atenção especial deste artigo reside na observação do gênero fora de suas delimitações mais frequentes ou seguras. Aponta-se uma outra periodicidade para que se pense o noir e o neonoir no contexto italiano, bem como é considerado o potencial de sobrevivência do gênero, em sua condição neonoir, em uma narrativa fílmica que traz enfaticamente elementos da comédia, definindo-se assim o objetivo central do trabalho. Dadas essas particularidades, compreende-se a proposta de um ponto de vista inovador, destacando-se que também traz a abordagem do noir para além de sua categorização mais comum, centralizada na morte, no crime e na violência. Valoriza-se aqui a observação do hedonismo, aspecto considerado em pesquisas anteriores do autor ${ }^{1}$ e que, através dos elementos beleza e prazer, complexifica o potencial de observação da narrativa.

Para o desenvolvimento metodológico do artigo, conta-se com o amparo da análise fílmica, através dos autores Jacques Aumont e Michel Marie (2009), e Francis Vanoye e Anne Goliot-Lété (2009). A análise se dá de um modo fluído, de acordo com as potencialidades da análise fílmica, que permitem essa opção, captando-se elementos significativos para os objetivos do trabalho, em conformidade com os pressupostos do noir e neonoir e suas percepções no contexto italiano. São observados planos, cenas ou sequências que melhor funcionam para as observações e ilustrações pertinentes. De acordo com a conveniência do trabalho, às observações de ordem mais descritiva são acrescentadas as de ordem interpretativa, recuperando os conhecimentos teóricos quando se fazem necessários para a melhor compreensão do que se deseja mostrar.

\footnotetext{
${ }^{1}$ Os referenciais teórico e metodológico deste texto são construídos a partir da tese do autor e de sua pesquisa de Pós-doutorado. O panorama de estudo relacionado ao gênero noir e sua sequência, ou neonoir, no contexto italiano, tem amparo no estágio sanduíche de doutorado do autor, realizado na Università degli Studi di Salerno, com bolsa Capes, sob orientação do Prof. Luigi Frezza, e que contribuiu para a elaboração da tese de doutorado, intitulada Cinema noir: as marcas da morte e do hedonismo na atualização do gênero (AUGUSTI, 2013). A tese foi desenvolvida no PPGCOM da PUCRS, com orientação da Profa Dr ${ }^{a}$ Cristiane Freitas Gutfriend. Já o pós-doutorado, foi realizado no PPGCOM da UFRGS, de novembro de 2015 a outubro de 2016, sob a supervisão da Profa Dr ${ }^{a}$ Nísia Martins do Rosário, e com bolsa Capes PNPD. Como resultado deste último curso, foi publicado um primeiro artigo como capítulo de livro (2018), intitulado "Cinema noir italiano: o hedonismo e a femme fatale em Ossessione"; também foi produzido um segundo, intitulado "Cinema neonoir italiano: o hedonismo e a femme fatale contemporânea". Ambos foram adaptados para apresentações em eventos, tendo sido as adaptações também publicadas em anais.
} 


\section{Brazilian \\ Creative Industries}

Em um primeiro momento, apontam-se algumas características basilares do gênero noir, considerações do neonoir, e suas adaptações para o contexto italiano. Depois, apresentam-se alguns aspectos de ordem metodológica, para que se perceba melhor a operacionalização da análise e a pertinência das escolhas metodológicas. Em seguida, procede-se à análise propriamente dita, respeitandose a orientação descrita no parágrafo anterior. Por fim, as considerações finais intencionam fechar as constatações possiveis com os aspectos mais centrais de observação do trabalho, situando o neonoir italiano de acordo com os aspectos descritos e analisados.

\section{NOIR CLÁSSICO E O NEONOIR NO CONTEXTO ITALIANO}

Noir é um termo advindo da expressão "novela escura", que começou a ser utilizado na França, no século XIX, delineando as obras de escritores que produziam literatura com características de mistério, atmosferas mais sombrias e que também faziam referências a sonhos. Já o termo film noir foi atribuído por franceses para aludir a alguns filmes policiais americanos da década de 1940 até o final da década de 50. Decorrente dessa noção, geralmente se compreende o neonoir a partir de refilmagens que iniciaram após a década de 60, servindo também para a atualização do gênero.

Destaca-se que foi a riqueza e a complexidade do gênero que valorizaram essas obras (filmes considerados noir) como cinema noir. Silver e Ursini (2004) questionam como esses filmes se tornaram uma das principais influências nas duas gerações seguintes de cineastas, incluindo nomes como Roman Polanski, Francis Ford Coppola, François Truffaut, Martin Scorsese, Claude Chabrol, Lawrence Kasdan, Luc Besson, Quentin Tarantino, Takeshi Kitano, David Fincher, Bertrand Tavernier, Stephen Frears, Spike Lee, Bryan Singer e Neil Jordan. Com base em realizadores como esses, o chamado neonoir se manteve intacto durante mais de três décadas (SILVER; URSINI, 2004). Considera-se, entretanto, que o neonoir nunca deixou de ser realizado.

As técnicas de iluminação fraca, câmera fora de centro e planos sombreados e claustrofóbicos chegaram aos Estados Unidos com cineastas imigrantes, que lançaram grandes marcos do gênero. Apesar de o estilo ter nascido na Europa, os temas pertenciam às cidades americanas, e a inspiração buscava histórias de crimes de James M. Cain, Raymond Chandler, Dashiell Hammett e Cornell Woolrich.²

No que tange ao cinema noir italiano, destaca-se que, dos anos 50 a 70 foi muito ousado, sendo, conforme Frezza (2012), fortemente portador de uma modernidade da linguagem, por isso se apresentam

\footnotetext{
${ }^{2}$ De acordo com Bergan (2009).
} 


\section{Brazilian \\ Creative Industries}

mais cenas de sexo, como em Aquele caso maldito (Un maledetto imbroglio - Pietro Germi, 1959), o batom (/l rossetto - Damiano Damiani, 1960), Milano calibro 9 (Fernando di Leo - 1972) e La donna della domenica (Luigi Comencini - 1975). Todos esses títulos podem ser considerados bons exemplos do noir italiano, apesar de Frezza afirmar que o grande filme noir italiano é Aquele caso maldito. O pesquisador também defende que o filme Processo Allá città (Luigi Zampa - 1952) é um grande noir. Ressalta-se que, com exceção do último título, todos os demais não correspondem ao período geralmente defendido para delimitar o noir clássico (entre 1941 e 1958), considerando-se, então, a especificidade do noir italiano também em relação ao período.

Frezza defende que podemos falar de neonoir italiano apenas a partir dos anos 90 . 0 crítico Giuseppe Cozzolino (COZZOLINO; CAPRARA, 2012) alonga ainda o período para a segunda metade da década de 90 em diante.

No que diz respeito mais especificamente aos elementos necessários para compor um filme noir, destacam-se, de acordo com Borde e Chaumeton (1958): um crime; a perspectiva dos criminosos, às vezes superando a da polícia; uma visão invertida das tradicionais fontes de autoridade, acentuando a abordagem da corrupção policial; alianças e lealdades instáveis; a femme fatale; violência bruta; motivação e mudanças em complôs bizarros. Conforme Silver e Ursini, é possivel identificar alguns temas recorrentes nas produções noir: o crime perfeito; o pesadelo fatalista; o peso do passado; amor em fuga; a violência masculina; as mulheres; o detetive particular; e perversidade e corrupção.

O filme noir traz a mulher como elemento fundamental. Ainda que não the seja oferecido o mesmo espaço que é dado ao protagonista, as ações da primeira alteram e direcionam a trama. Mattos (2001) alerta para a ideia de que a desconfiança dos homens em relação às mulheres, que foram encorajadas a trabalhar nas fábricas durante a Guerra, correspondendo ao seu dever patriótico, além de cuidar da casa e da família, gerando o receio dos homens quanto à competitividade, seria responsável pela misoginia, verificada no tratamento das personagens femininas.

A importância da Segunda Guerra para a definição do noir, com o consequente estabelecimento de seus principais elementos, também é considerada por Mascarello (2006), para quem a figura noir mítica da mulher fatal deve ser entendida nesse contexto. "[...] a femme fatalemetaforiza, do ponto de vista masculino, a independentização alcançada pela mulher no momento histórico do pós-guerra." (MASCARELLO, 2006, 182). Nesse período, o autor destaca que as mulheres foram treinadas para substituir os homens no trabalho, já que eles estavam no front. Assim, defende que ao operar a transformação dessa mulher em sedutora malévola, o noir busca reforçar a masculinidade ameaçada, restabelecendo de forma simbólica o equilíbrio perdido. Entretanto, considera-se que no noir não temos mais a figura mítica do herói, mas sim 


\section{Brazilian

a ideia de uma personagem masculina ambígua, falível e que por si só se torna vulnerável, não podendo ter sua falta de sorte atribuída somente à femme fatale.

Nesse contexto, a femme fatale, uma mulher interesseira e perigosa, é em grande parte responsável pela ruína do homem que se deixa envolver por seu poder de sedução. Essa perspectiva vem aliada à busca pelo prazer e é a que determina o hedonismo, amparado pela figura da femme fatale, como uma das tipologias relevantes para a condução da análise proposta para este trabalho.

A perspectiva hedonista associada à beleza física e ao prazer consequente corresponde, a princípio, a uma das principais armas da femme fatale para seduzir e vitimar o homem que desperta as possibilidades de ascensão e domínio dessa mulher. Ela busca provocar o prazer do homem e utiliza para isso sua beleza e inteligência. Mas as contradições da mulher do noir compõem, geralmente, o cenário que determina sua própria desgraça.

A femme fatale do noir clássico representava ameaça ao patriarcado, mas ao final ela paga por isso, com Zizek (2009) defendendo que, conforme a teoria feminista do cinema, ela é punida ao nível da linha narrativa explícita. Ao contrário dessa femme fatale dos anos 40, que, permanece uma presença espectral fugidia (o que the confere certo poder), a nova femme fatale [do neonoir dos anos 80 e 90, conforme Zizek - mas que se entende aqui como abarcando um período mais amplo para o neonoir] apresenta uma agressividade sexual frontal também física, além da verbal. Esse tipo de personagem agora mercantiliza e manipula diretamente a si mesma. Mas seu triunfo é da ordem do material. (ZIZEK, 2009).

Esse panorama contemporâneo de valorização hedonista, que pode ser percebido no mínimo em âmbito ocidental, ampara muito as narrativas construídas na atualização do noir. Tem-se em vista, portanto, o hedonismo, amparado pela femme fatale. Entretanto, atenta-se ainda, nas observações a seguir, para o viés mais comumente considerado no gênero: a morte, a violência e o crime, que instauram a atmosfera noir, como tradicionalmente é compreendida. 0 ponto de maior novidade nesta proposta reside, entretanto, no mapeamento de elementos característicos do noir ou neonoir em um filme que transitaria mais facilmente pelo gênero da comédia.

\section{ORIENTAÇÕES METODOLÓGICAS}

A partir dos objetivos do trabalho, indica-se como orientação metodológica a análise fílmica. Para amparar essa proposta, são utilizados principalmente os autores Jacques Aumont e Michel Marie (2009), e Francis Vanoye e Anne Goliot-Lété (2009).

Os primeiros autores, baseados na Análise Fílmica, ressaltam a ideia de extrair do filme certos materiais para que sejam avaliados esses recortes, possibilitando-se sua análise em separado e não mais 


\section{Brazilian

em conjunto com os demais materiais da obra, permitindo-se descobrir o que não seria possivel quando tomado o filme como um todo. Após a seleção desses materiais, conforme os pressupostos analíticos, eles são descritos e interpretados. Reitera-se que este último processo dá-se de forma fluida, trazendo a interpretação quando os pressupostos teóricos se fazem relevantes para elucidar aspectos da descrição, efetivando o processo analítico e permitindo ao leitor compreender o que a simples apreciação do filme ou o recorte de certos elementos dificultariam alcançar em termos de entendimento.

A análise filmica supõe duas condições (AUMONT et al, 2009): a constituição de um estado intermediário entre a própria obra e a sua análise, e a modificação mais ou menos radical das condições de visão do filme. Outra observação relevante é que a compreensão de um filme pode partir de sua constituição enquanto produto cultural relativo a um contexto social e histórico particular (VANOYE; GOLIOT-LÉTÉ, 2009). A complexidade do noiré construída em muito devido a isso.

Com base nos elementos e características básicas do cinema noir a partir das principais orientações metodológicas indicadas, segue-se a operacionalização da análise do filme L'ultimo Capodanno. Entretanto, devido às pertinências da proposta, para a elaboração de um artigo, são destacados apenas alguns recortes do filme, com interpretações limitadas ao que se compreende representar o cerne da obra, em conformidade com os objetivos do trabalho.

\section{L'ULTIMO CAPODANNO: ENTRE O NOIR E A COMÉDIA}

Conforme o professor de cinema, escritor, ensaísta e roteirista, Giuseppe Cozzolino (CAPRARA; COZZOLINO, 2016), existem vários filmes que ainda hoje bem ou mal brotam na filmografia italiana inspirados na atmosfera noir, pulp. Cita Io non ho paura, de Salvatores (2003); Come Dio comanda, do mesmo diretor (2008); Nero bifamiliare, de Federico Zampaglione (2007); e L'ultimo Capodano, de Marco Risi (1998). Destaca que o último diretor realiza vários filmes considerados noir, mais de compromisso civil, como Mary per sempre (Deliquência atrás das grades - Mary para sempre, 1989), com Michele Placido no elenco; Ragazzi fuori (Garotos de rua, 1990); chegando a L'ultimo capodano, um conto de Niccolò Ammaniti, que para Cozzolino é um conto grotesco pulp, mas divertidíssimo. Destaca que o filme foi muito maltratado pela crítica e o público, mas que talvez seja até um pouco antecipado em relação ao seu tempo, no sentido de ser visionário.

O noir tem por base uma atmosfera de angústia, que neste filme é quebrada pelo tom de comédia. É sabido que o gênero noir trabalha com o recurso do humor negro, que muitas vezes permite os respiros necessários em momentos de tensão. Entretanto, em L'último Capodanno temos o humor em primeiro plano. Os recursos tradicionais do noir são muito presentes, mas são utilizados de modo subversivo. Ainda 


\section{Brazilian \\ Creative Industries}

assim, Cozzolino defende que o filme pode ser considerado um neonoir italiano e, desse modo, faz-se um mapeamento de elementos noir em alguns momentos da narrativa, tentando-se compreender seu funcionamento nesta obra. Elementos que reportam ao humor característico da obra também serão considerados, em alguma medida, seja porque conversam com o habitual humor negro, próprio do noir desde seu período clássico, seja porque são necessários para que se compreenda a abordagem do humor no filme em questão. Podem ser destacados planos, cenas ou sequências, conforme a pertinência para a elucidação do que se quer apontar. Fotogramas são apontados para ilustrar alguns elementos da observação.

O filme narra a história, sempre dramática, de diversas personagens que convivem em um mesmo condomínio. Mas toda a construção desses dramas vem sempre costurada com elementos de humor. É véspera de Ano Novo (o título L'ultimo Capodanno pode ser traduzido como O último Ano Novo). Dentre tantas histórias confusas que se cruzam, tem-se o jantar de Giulia (interpretada por Monica Bellucci), em que planeja se vingar do marido, Enzo (Marco Giallini), que tem um caso com sua amiga, Lisa (Francesca d'Aloja); a festa da condessa Scintilla (Maria Monti), que é destruída por um grupo de pessoas relacionadas ao seu gigolô, Gaetano, (Giuseppe Fiorello); uma mulher desesperada (Filomena, interpretada por Ludovica Modugno), que tenta se suicidar com remédios, devido à ausência de seu marido desaparecido; os preparativos de uma falsa família perfeita, que está ansiosa em passear com seu Dodge vintage; um advogado, pai de família (Rinaldi, interpretado por Alessandro Haber), que vestido com roupas de couro ou lingerie, é perseguido em seu escritório por uma prostituta (Sukia, interpretada por Federica Virgili), contratada por ele para uma performance de sadomasoquismo, enquanto três criminosos invadem o local e o amarram em situação ridícula; e dois rapazes (Cristiano, interpretado por Claudio Santamaria; e Ossadipesci, interpretado por Max Mazzotta) trancados em um quarto fumando drogas enquanto a mãe de um deles recebe os convidados para jantar. Os dramas avançam rumo à meia-noite, quando uma situação grotesca vai unir todas as personagens.

É justamente, nesta narrativa, o cruzamento de elementos característicos do noir e da comédia que constrói o tom dos acontecimentos. É assim que a invasão de uma casa, por três criminosos, em um cenário tipicamente noir, com fraca iluminação, compõe uma cena bizarra e ao mesmo tempo cômica com personagens surpreendentemente envolvidos em situações ridículas. Também é desse modo que, por exemplo, uma senhora suicida, talvez à beira da morte, é colocada em uma situação que não provoca angústia e sim riso, dependurada sobre um homem com roupas íntimas femininas, enquanto é ameaçado por três invasores. Temos um plano de conjunto que nos faz perceber uma situação de vitimização, com pessoas amarradas, a luz escassa de um abajur (elemento característico dos filmes noir mais tradicionais), o predomínio do preto nas roupas, que acentua o lado sombrio das personagens. Ao mesmo tempo, é 


\section{Brazilian

evidente a acentuada proposta de humor com a situação vexaminosa das vítimas, notória quando se verifica, por exemplo, que a mulher do homem travestido liga para ele juntamente com os filhos, enquanto o marido precisa disfarçar o embaraço que o acomete.

Figura 1 - 0 pai de família, dado como pervertido, é imobilizado por criminosos, junto à senhora grogue com o efeito da medicação que tomou para se suicidar.

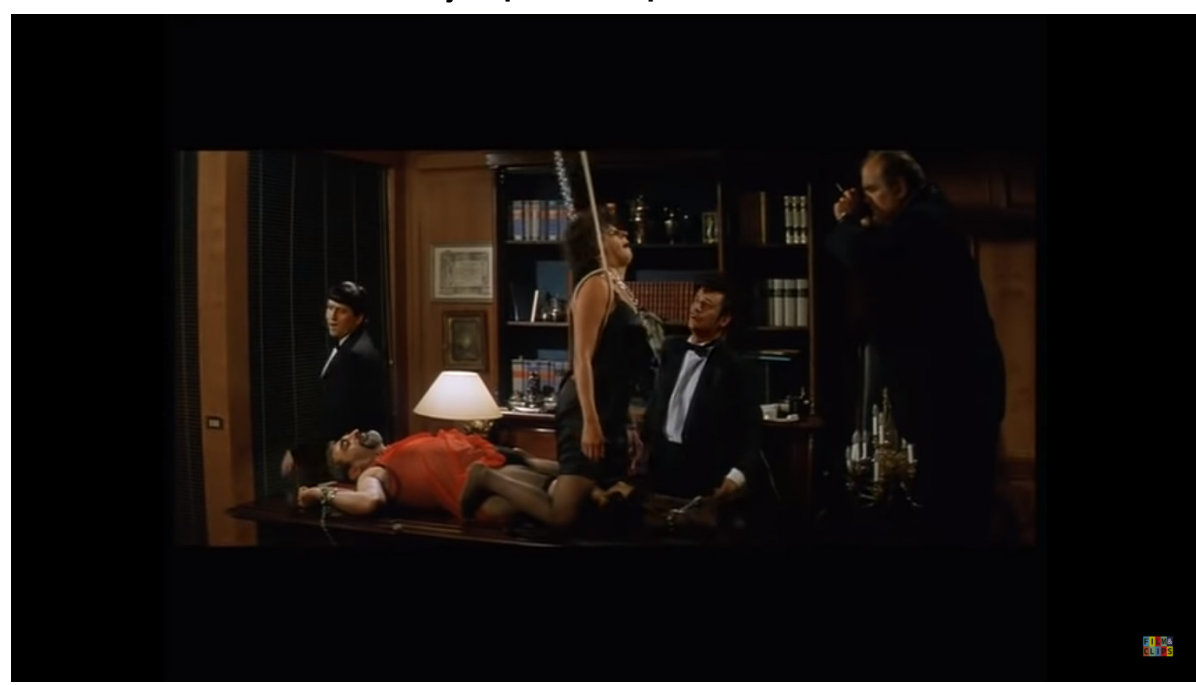

Fonte: Risi (1998)

Outro recurso comumente utilizado pelo noir para auxiliar na construção de sua atmosfera é a banda sonora. Em L'ultimo Capodanno, entretanto, em uma das primeiras cenas, quando temos uma construção visual tipicamente noir, com alusão ao insólito, escuridão, névoa, iluminação artificial e escassa, a trilha é animada, antecipando algo jocoso. É o anúncio do tom do filme, que se desenvolve todo com essa base de sustentação da narrativa. 


\section{Brazilian \\ Creative Industries \\ Journal}

Figura 2 - Elementos típicos do noir compõem a imagem.

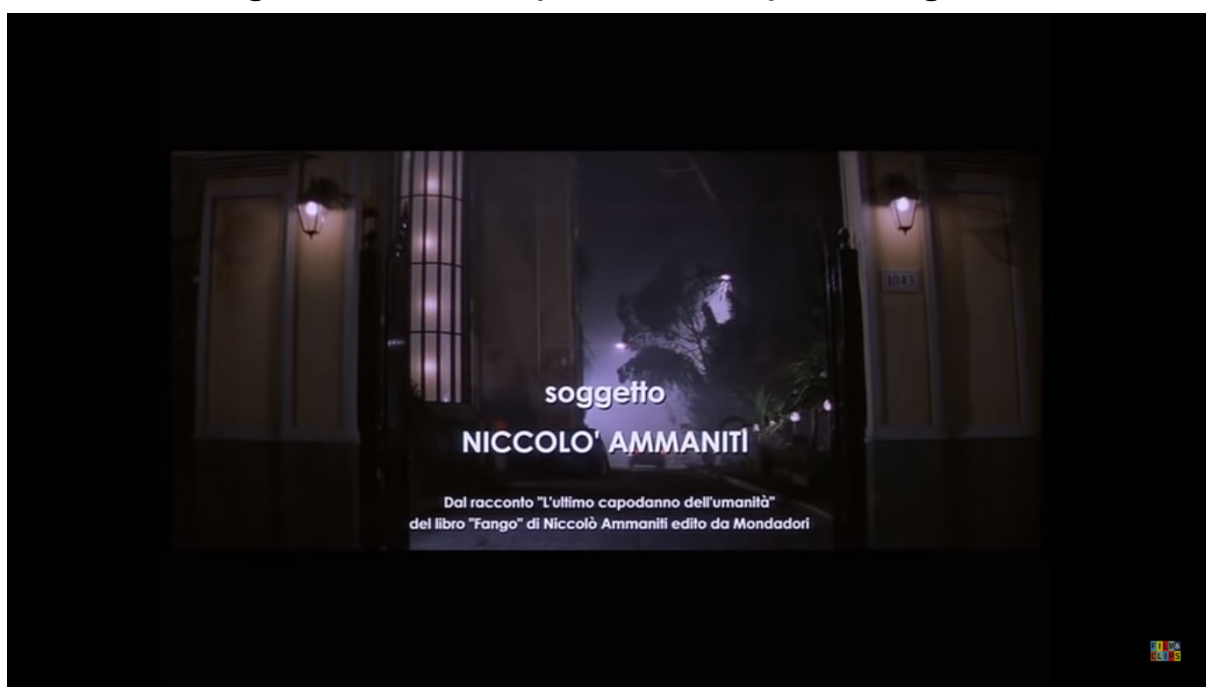

Fonte: Risi (1998)

Tem-se, ainda, a nudez masculina, aqui representada mais acentuadamente pelo gigolô Gaetano, que é obrigado pela condessa Scintilla a se despir, quando ela diz: "Eu te pago". Embora o neonoir valorize acentuadamente a nudez feminina, os filmes deste gênero na Itália trazem muito frequentemente belos e sedutores homens, que tantas vezes representam a perdição para a mulher que se apaixona por eles, numa subversão ao papel comumente atribuído à femme fatale. Essa cena não é menos engraçada, quando a condessa abre os braços e ordena, desequilibrada: "Abraça-me, Gaetano!".

Figura 3 - A poderosa condessa domina seu homem objeto.

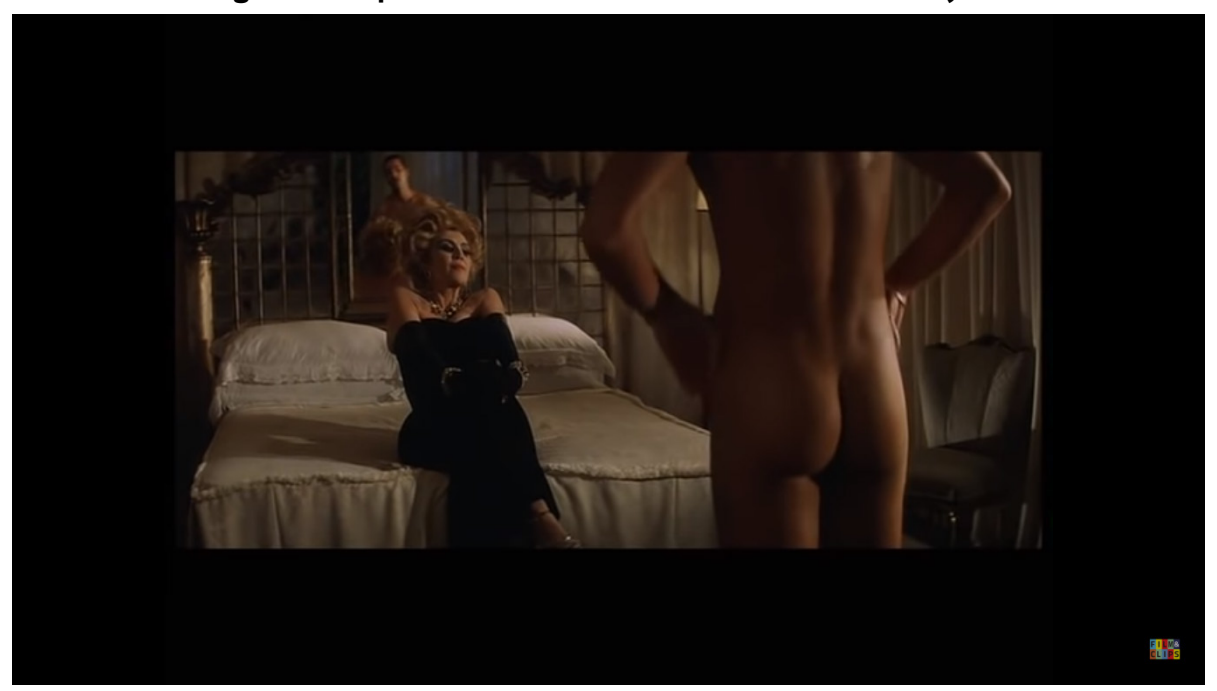

Fonte: Risi (1998) 


\section{Brazilian \\ Creative Industries}

Em outra cena, a belíssima Giulia, apenas de soutien e sapatos de salto, após chorar, gritar e vomitar dentro de uma gaveta, além de quebrar retratos de seu marido e da amiga com quem o marido a traiu, e colocar fogo no que sobrou deles, recebe o marido absolutamente bem composta, mesmo tendo descoberto a traiç̧ão.

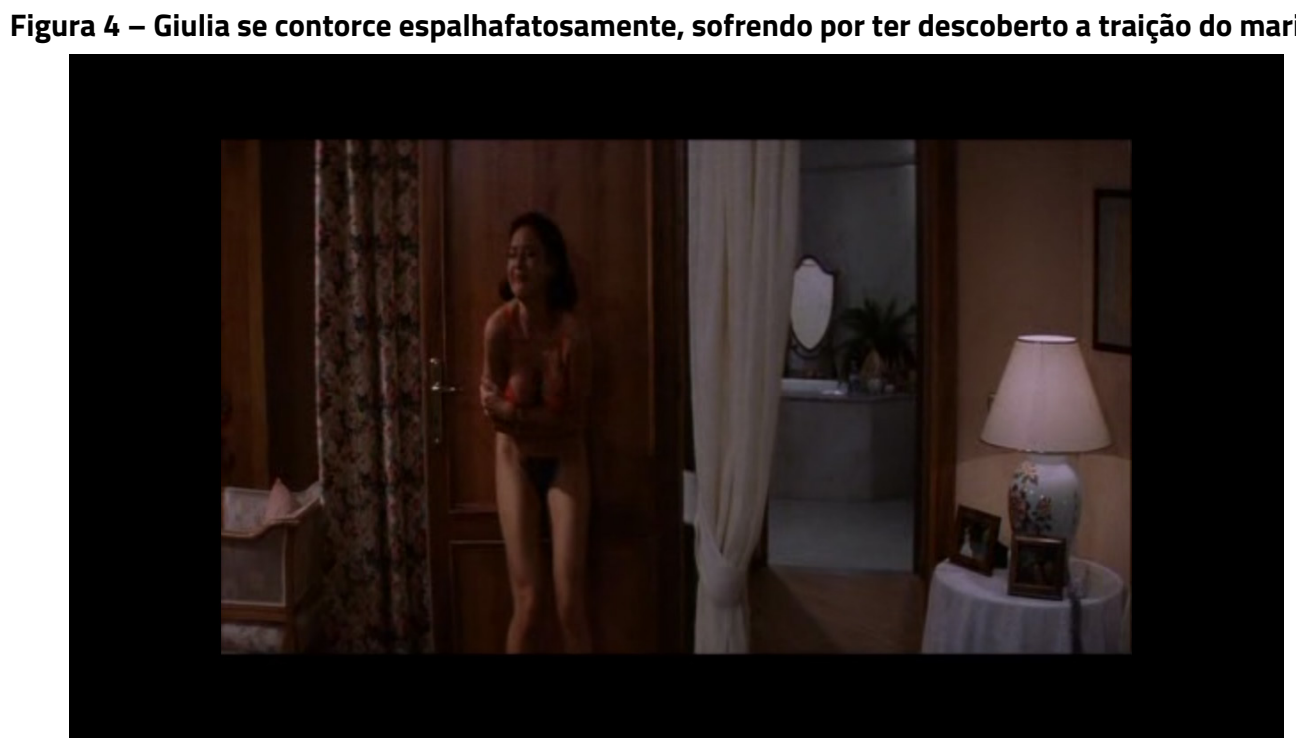

Fonte: Risi (1998)

Mas um plano fechado, ao estilo noir, atesta a periculosidade da mulher, como normalmente se apresenta o caráter de uma femme fatale. Não se intenta aqui classificar Giulia ou outra personagem como uma femme fatale, mas apontar um pouco o modo de construção dessa personagem, que incorpora características da femme fatale, e que vai destruir o homem que com ela se envolveu e que a frustrou em relação às expectativas do casamento. 


\section{Brazilian \\ Creative Industries \\ Journal}

Figura 5 - Giulia percebe, séria e perigosamente, a chegada de seu marido.

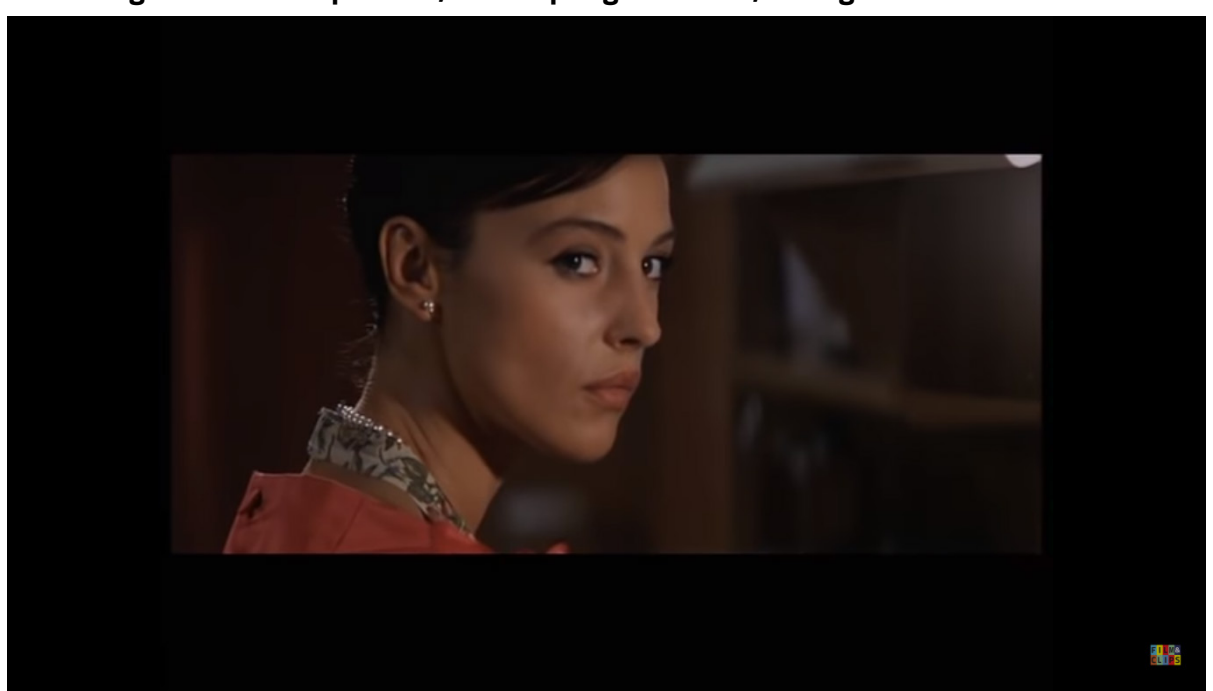

Fonte: Risi (1998)

Na sequência do plano de vingança de Giulia, a câmera cada vez mais se aproxima da personagem, revelando novamente sua periculosidade, enquanto ela se aproxima dos presentes no jantar em sua casa com um arpão. A maquiagem exageradamente borrada e sua expressão mecânica soam risíveis, ainda que as sombras no quadro (elemento tipicamente noir, aproveitado do cinema expressionista alemão, e que representa a obscuridade da personagem) e a arma anunciem uma morte.

Figura 6 - Giulia se revela armada para seus convidados.

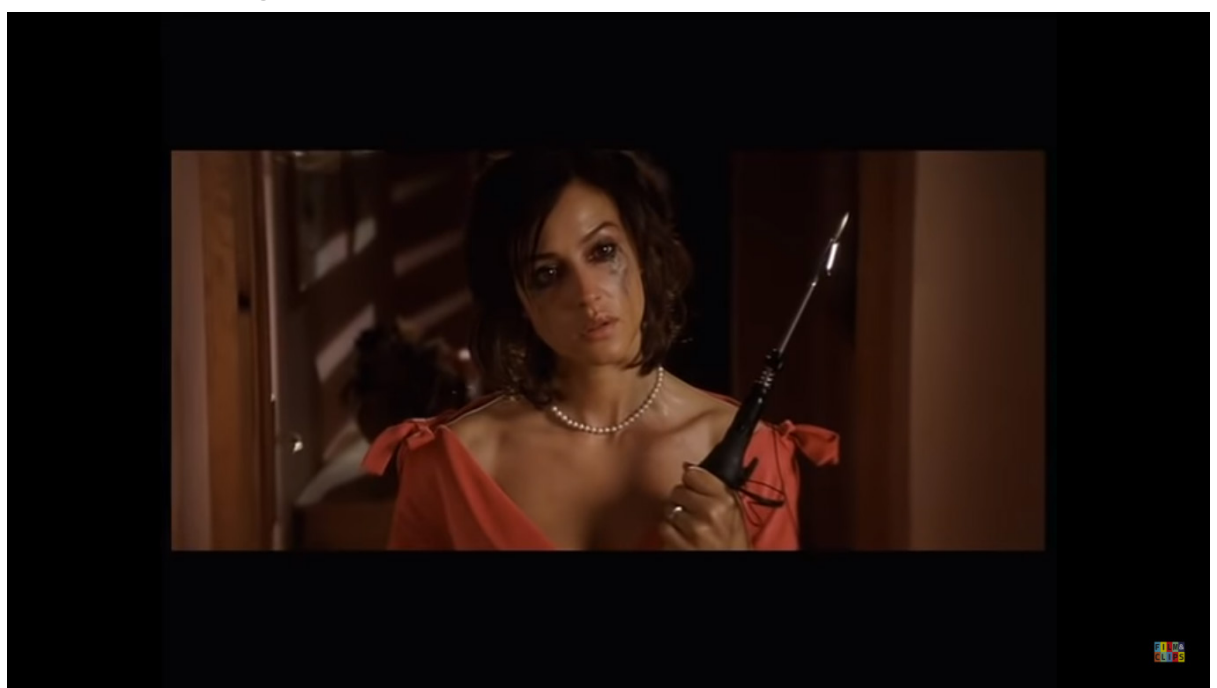

Fonte: Risi (1998) 


\section{Brazilian

Giulia, dominando a cena, empreende uma vingança que navega entre o pesadelo fatalista e a comédia, que é evocada em meio ao sangue e ao modo ridículo como os perseguidos são atingidos pela arma de Giulia: a amiga desmaia após ser surpreendentemente golpeada no rosto com o arpão que Giulia porta e que dispara no peito do marido, provocando histeria e fuga imediata de todos os presentes. Sobre o pesadelo fatalista, considera-se:

O mundo do noir é essencialmente um mundo de pesadelo. Está repleto de estranhos sincronismos, acontecimentos inexplicáveis e encontros do acaso, que criam uma corrente de acontecimentos que por fim arrastam o infeliz protagonista para o seu fim pressagiado. Alguns podem conseguir escapar ao pesadelo no último minuto e voltar a uma normalidade relativa. (SILVER; URSINI, 2004, p. 39).

Mas esse não é o caso do marido traidor em L'ultimo capodanno, atingido impiedosamente pelo arpão de Giulia.

Figura 7 - Junto à Giulia, veem-se a amante ferida e o marido esvaindo-se em sangue após ter sido atingido pelo arpão.

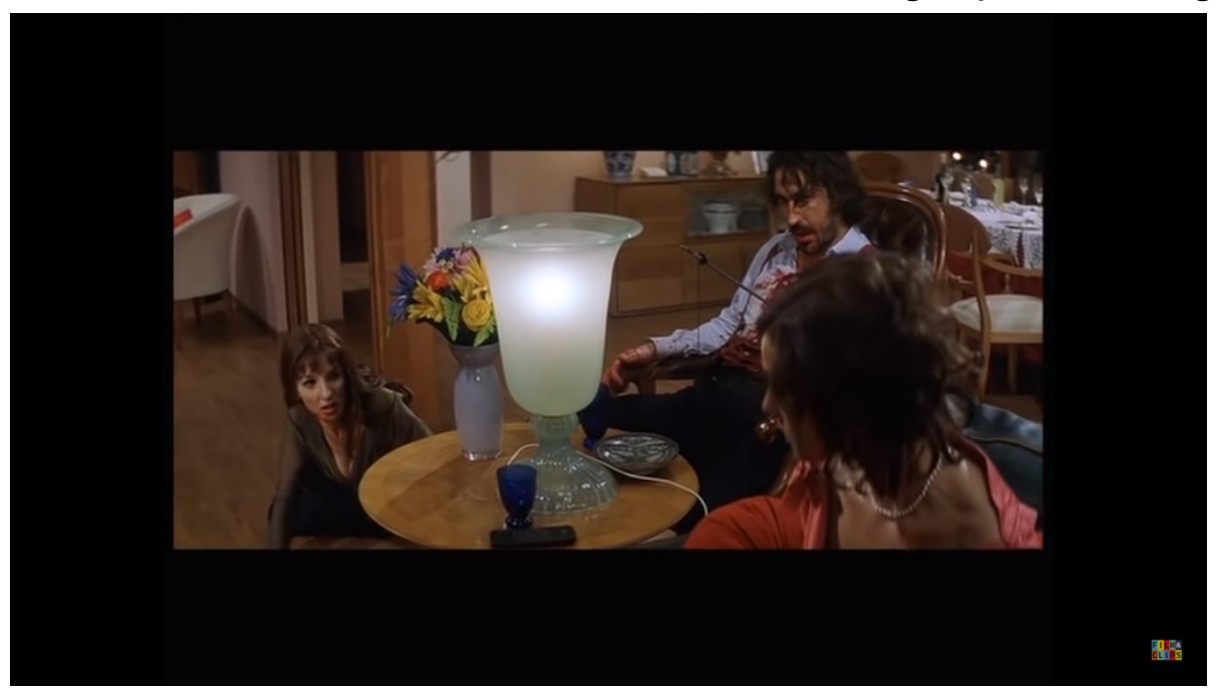

Fonte: Risi (1998)

Já a familia aparentemente perfeita se envolve com o grupo que invadiu a festa da condessa e, enquanto o avô dispara com uma grande arma de fogo em um dos invasores, perde a mão e adentra à casa com sangue espirrando fartamente pelo ambiente, em uma rememoração do estilo Tarantino, que inspira fortemente os filmes neonoir italianos. 


\section{Brazilian \\ Creative Industries \\ Journal}

Figura 8 - 0 sangue farto, típico do neonoir, aqui organizado para acentuar o humor.

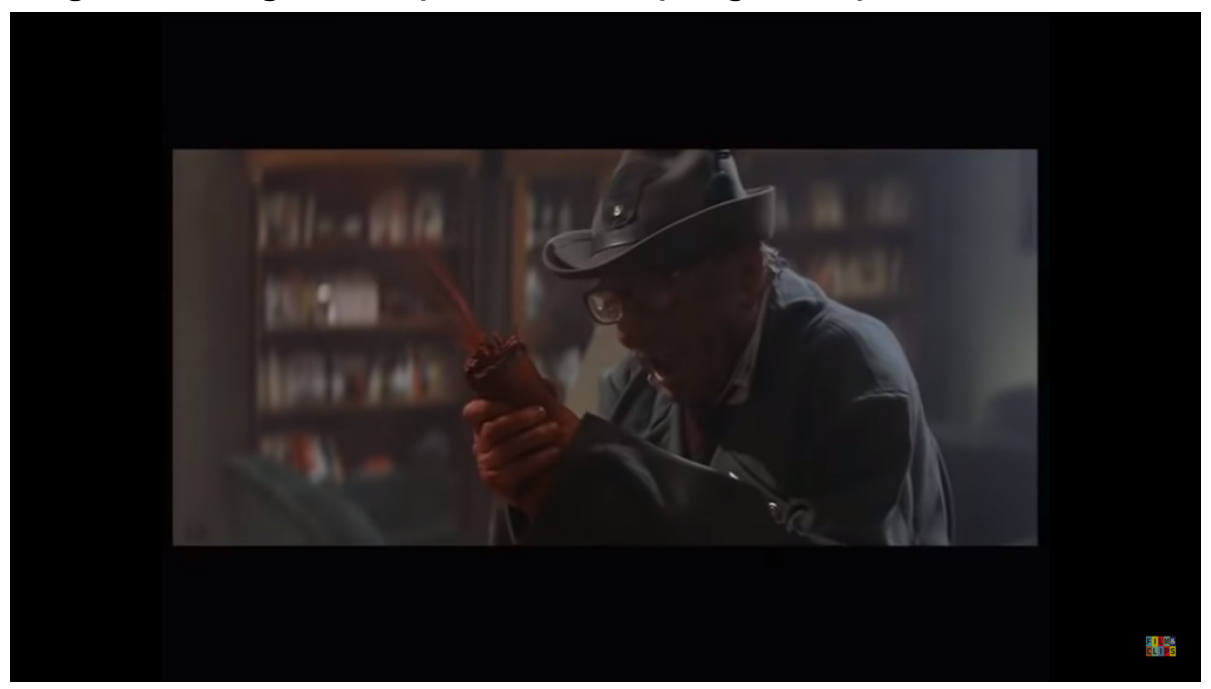

Fonte: Risi (1998)

A mão é revelada no prato de sobremesa, em uma composição perfeita, após ter sido encontrada pela neta, que caminha séria e concentrada em sua busca, ao som dançante de Elvis Presley.

Figura 9 - A neta, com absoluto autocontrole, revela a mão perdida do avô.

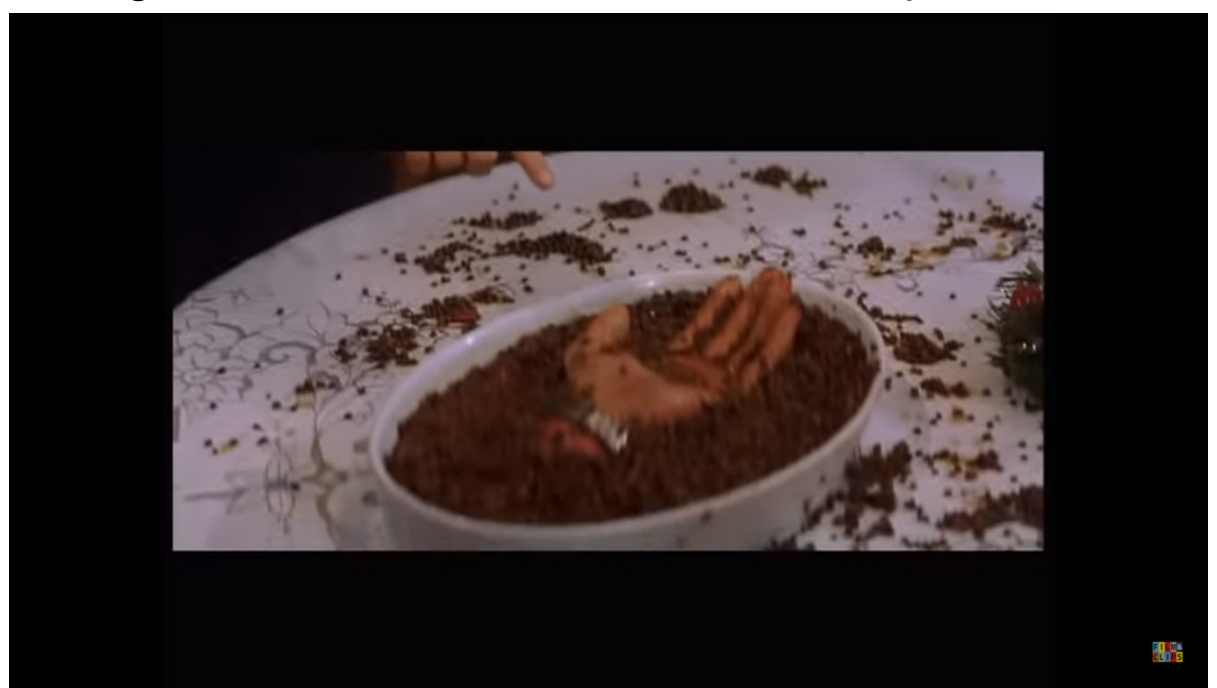

Fonte: Risi (1998)

Ao final, durante a contagem da virada de ano, uma explosão fatal com uso de dinamite destrói o condomínio. O único sobrevivente que a narrativa mostra é justamente o responsável pelo acontecimento: 


\section{Brazilian \\ Creative Industries}

Ossadipesce, que, demasiado alterado pelo consumo de drogas, não percebeu o incidente que estava prestes a cometer.

Figura 10 - Ossadipesce, surpreendentemente, emerge do caos e sobrevive à explosão provocada por ele.

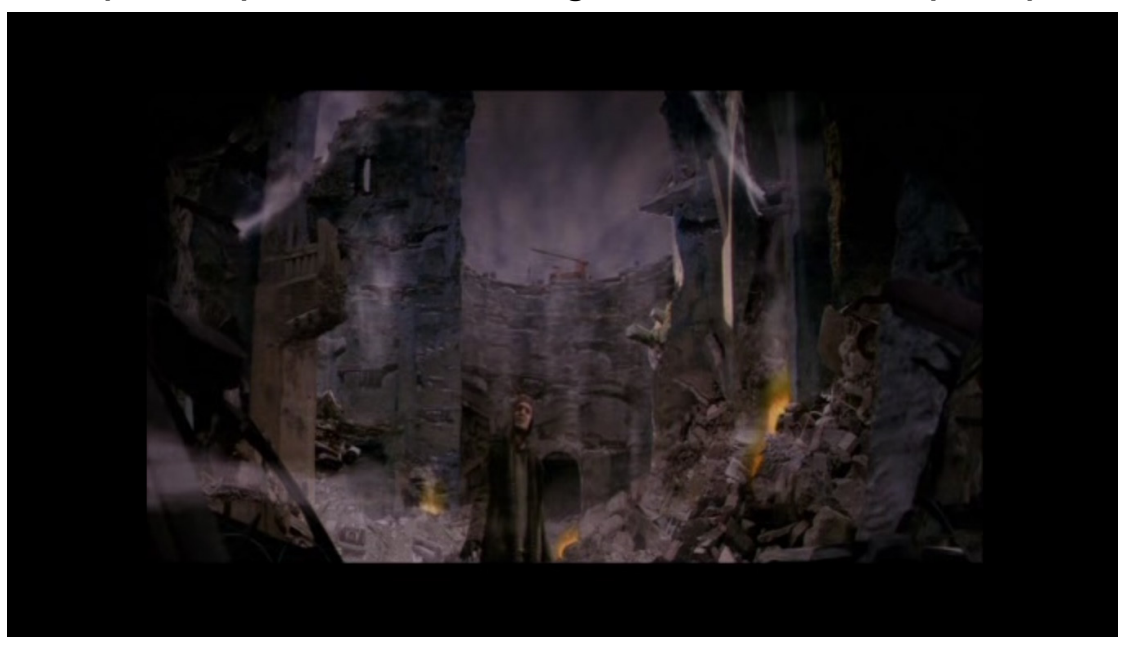

Fonte: Risi (1998)

\section{CONSIDERAÇÕES FINAIS}

De acordo com Frezza, até os anos 70 se pode falar sobre gêneros nos filmes italianos. Depois, estariam acabados os filmes de gêneros, não significando que não existam filmes singulares, mas já não têm grandes características como antes. Em 2000, surgem filmes de autor e não mais de gêneros, defende Frezza, o que corrobora a ideia de que tais filmes "neonoir" representam de certa forma uma atualização do noir, mas não podem ser classificados como pertencentes a qualquer outro gênero. Cada vez mais a ideia de gênero cinematográfico aponta para a hibridização dos filmes, através do cruzamento desses gêneros.

Defende-se, portanto, a ideia de que o neonoir corresponde a um rearranjo do noir clássico, o que sugere a sua penetração em outros territórios, antes não tão contaminados pelo noir, já que este tinha seu próprio território bem definido e as delimitações dos gêneros pareciam ser mais claras. Verificamos a evolução da técnica, possibilitando o aparecimento do sangue agora colorido e mais impactante, o que potencialmente intensifica os efeitos da violência e da morte.

No filme em questão, temos o noir garantindo sua sobrevivência com a contaminação da comédia. Seus elementos são rearranjados e sobrevivem, agora transformados e atualizados. É nessa perspectiva que podemos avaliar L'ultimo capodanno como um filme neonoir, distante da abordagem clássica do gênero, mas atualizado e assegurado em um contexto que lhe permite sobreviver. 


\section{Brazilian Creative Industries}

\section{REFERÊNCIAS}

AUGUSTI, A. R. Cinema noir italiano: o hedonismo e a femme fatale em Ossessione. In: NETO, Thaís Helena Ferreira (org.). Comunicação e jornalismo: conceitos e tendências 2. E-book. Ponta Grossa: Editora Atena, 2018.

AUGUSTI, A. R. Cinema noir: as marcas da morte e do hedonismo na atualização do gênero. 2013. 287 f. Tese (Doutorado em Comunicação Social) - Pontifícia Universidade Católica do Rio Grande do Sul, Porto Alegre, RS, 2013. Disponivel em: 446023 Substituição.pdf (pucrs.br). Acesso em: 24 jul. 2021.

AUMONT, J. et al. A estética do filme. 7. ed. Campinas: Papirus, 2009. 304 p.

AUMONT, J.; MARIE, M. A análise do filme. 1. ed. Lisboa: Texto e Grafia, 2009. 216 p.

BERGAN, R. Guia ilustrado Zahar cinema. 3. ed. rev. e atual. Rio de janeiro: Jorge Zahar Ed., 2009. 512 p.

BORDE, R.; CHAUMETON, E. Panorama del cine negro. Buenos Aires: Ediciones Losange, 1958.

CAPRARA, V.; COZZOLINO, G. Cinema noir e neonoir italianos: depoimento [19 de janeiro, 2016]. Napoli. Entrevista concedida a Alexandre Rossato Augusti.

FREZZA, L. Cinema noir e neonoir: depoimento [16 de maio, 2012]. Fisciano. Entrevista concedida a Alexandre Rossato Augusti.

L'ULTIMO capodanno. Direção: Marco Risi. Produção: Marco Risi, Maurizio Tedesco. Intérpretes: Max Mazzotta; Monica Bellucci; Giuseppe Fiorello. Itália: Sorpasso Film, Istituto Luce, Cinecittà, 1998, 109 min, son., color.

MASCARELLO, F. Film noir. In: MASCARELLO, Fernando (org.). História do cinema mundial. Campinas: Papirus, 2006. p. 177-188.

MATTOS, A. C. de G. de. 0 outro lado da noite: film noir. Rio de Janeiro: Rocco, 2001. 255 p.

SILVER, A.; URSINI, J. Film noir. Colônia: Taschen, 2004. 191 p.

VANOYE, F.; GOLIOT-LÉTÉ, A. Ensaio sobre a análise fílmica. 6. ed. Campinas: Papirus, 2009. 152 p.

ZIZEK, S. Lacrimae rerum: ensaios sobre cinema moderno. São Paulo: Boitempo editorial, 2009. 